Acta Crystallographica Section C

Crystal Structure

Communications

ISSN 0108-2701

\section{A tetragonal form of dysprosium orthomolybdate at room temperature}

\author{
Sesegma Dorzhieva, ${ }^{a}$ Ihor Chumak, ${ }^{\mathrm{b}}$ Angelina \\ Sarapulova, ${ }^{b *}$ Daria Mikhailova, ${ }^{b}$ Jibzema Bazarova ${ }^{a}$ and \\ Helmut Ehrenberg ${ }^{\mathrm{c}}$
}

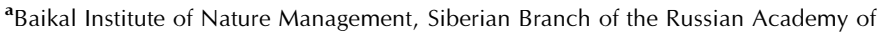
Sciences, Sakhyanova Street 6, Ulan-Ude, Russian Federation, ${ }^{\mathbf{b}}$ Institute for Complex Materials, IFW Dresden, Helmholtzstrasse 20, 01069 Dresden, Germany, and 'Karlsruhe Institute of Technology (KIT), Institute for Applied Materials (IAM), Hermann-von-Helmholtz-Platz 1, D-76344 Eggenstein-Leopoldshafen, Germany Correspondence e-mail: a.e.sarapulova@ifw-dresden.de

Received 15 June 2011

Accepted 18 August 2011

Online 15 September 2011

In the present tetragonal modification of dysprosium orthomolybdate, $\mathrm{Dy}_{2}\left(\mathrm{MoO}_{4}\right)_{3}$, the $\mathrm{Dy}$, one $\mathrm{Mo}$ and one $\mathrm{O}$ atom are located on a mirror plane with Wyckoff symbol $4 e$, while another Mo atom is located on a fourfold inverse axis, Wyckoff symbol 2a. A single crystal was selected from a polycrystalline mixture of the $\mathrm{Dy}_{2} \mathrm{O}_{3}-\mathrm{ZrO}_{2}-\mathrm{MoO}_{3}$ system and was stable at room temperature for at least three months. The structure refinement does not indicate the presence of $\mathrm{Zr}$ on the Dy sites (to within 1\% accuracy). Thus, the stabilization of the tetragonal form is due to disordered positions for a second $\mathrm{O}$ atom and split positions for a third $\mathrm{O}$ atom that also maintain the $\mathrm{DyO}_{7}$ coordination, which is not expected for short Dy-O distances [2.243 (6)-2.393 (5) A].

\section{Comment}

It is known that the molybdates of the rare earth elements show interesting fluorescence, laser, piezoelectric, ferroelectric and ferroelastic properties, and they are used as catalysts for the oxidation of organic compounds such as toluene and isobutene (Smet et al., 2001; Wang et al., 2008; Nassau et al., 1971; Wenxing et al., 1999). The crystal chemistry of molybdenum compounds is very rich because Mo adopts different oxidation states and therefore forms various coordination polyhedra, such as tetrahedra (Nassau et al., 1971), pyramids (Alonso et al., 2004) and octahedra (Gall et al., 2002). For example, Gall et al. (2002) synthesized molybdates $R_{4} \mathrm{Mo}_{4} \mathrm{O}_{11}(R=\mathrm{Gd}-\mathrm{Tm})$ with an average oxidation state for Mo of +2.5 and explained the stabilization of the crystal structures through the distortion of trans-edge-sharing Mo octahedra, based on theoretical calculations. With higher oxidation states Mo forms fivefold oxygen coordination, as in the $\mathrm{Dy}_{2} \mathrm{MoO}_{6}$ structure (Alonso et al., 2004).
Rare earth molybdates with $M_{2}\left(\mathrm{MoO}_{4}\right)_{3}$ stoichiometry exist in several polymorphs, depending on the temperature and the specific rare earth element (Nassau et al., 1971). A hightemperature $\beta$-form is stable at temperatures above 1023$1153 \mathrm{~K}$. The transition from the $\beta$-modification to the roomtemperature $\alpha$-form is kinetically prevented during cooling and takes place via a $\beta^{\prime}$ phase, which is metastable at room temperature for a long time. For example, crystals of $\mathrm{Gd}_{2}\left(\mathrm{MoO}_{4}\right)_{3}$ exist in the metastable Pba2 (Keve et al., 1970) form under ambient conditions for years, although the stable low-temperature form is monoclinic (Nassau et al., 1971). Both the tetragonal and orthorhombic polymorphic modifications contain a network of corner-sharing polyhedra, in which Gd and Mo cations are coordinated by seven and four $\mathrm{O}$ atoms, respectively.

Borchardt \& Bierstedt (1967) showed that $\mathrm{Gd}_{2}\left(\mathrm{MoO}_{4}\right)_{3}$ and the isostructural molybdates of $\mathrm{Sm}, \mathrm{Eu}, \mathrm{Tb}$ and $\mathrm{Dy}$ undergo ferroelectric phase transformations in the temperature range $423 \mathrm{~K}<T_{0}<463 \mathrm{~K}$. Gadolinium molybdate, $\mathrm{Gd}_{2}\left(\mathrm{MoO}_{4}\right)_{3}$, with a ferroelectric-ferroelastic transition temperature of about $433 \mathrm{~K}$, crystallizes in the space group Pba2 (metastable form) below the phase transition and in the space group $P \overline{4} 2_{1} m$ above it (Jeitschko, 1972). The paraelectric structure at elevated temperature approaches the average structure of the two ferroelectric-ferroelastic orientations (Jeitschko, 1972). Zou et al. (1999) mentioned that the $\beta$-modification of $\left(\mathrm{Nd}_{0.023} \mathrm{Gd}_{0.977}\right)_{2}\left(\mathrm{MoO}_{4}\right)_{3}$ with tetragonal symmetry can exist at room temperature.

Dysprosium molybdate, $\mathrm{Dy}_{2}\left(\mathrm{MoO}_{4}\right)_{3}$, shows a ferroelectric-ferroelastic transition below 418 K (Roy et al., 1989). According to X-ray powder diffraction, the ferroelectric phase crystallizes in orthorhombic symmetry (space group $\mathrm{Pba2}$;

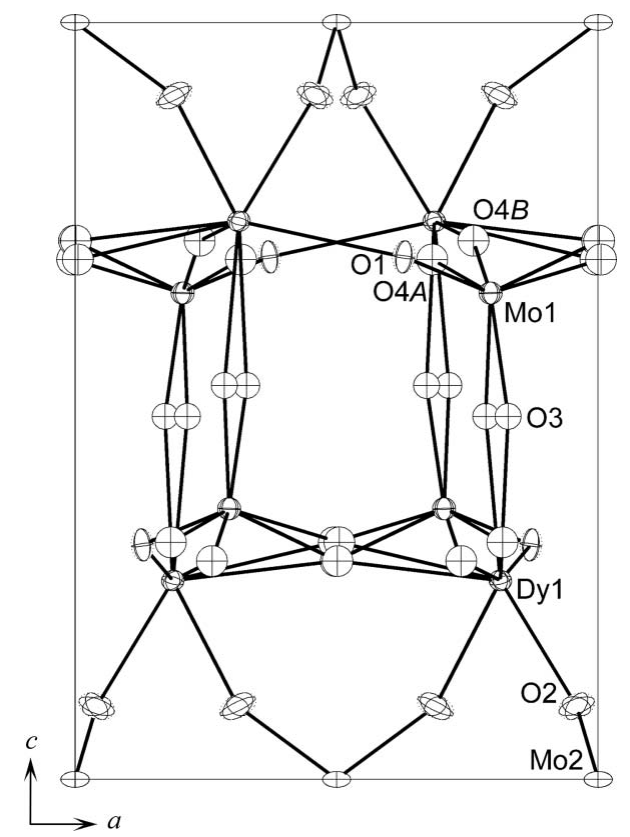

Figure 1

The $\mathrm{Dy}_{2}\left(\mathrm{MoO}_{4}\right)_{3}$ tetragonal unit cell, showing the atom-numbering scheme. Displacement ellipsoids are drawn at the $70 \%$ probability level. 


\section{inorganic compounds}

Roy et al., 1989). Above $1303 \mathrm{~K}$, a reconstructive phase transition into a cubic form of $\mathrm{Dy}_{2}\left(\mathrm{MoO}_{4}\right)_{3}$ was reported (Roy et al., 1989; Brixner, 1973).

In this work, single crystals of $\mathrm{Dy}_{2}\left(\mathrm{MoO}_{4}\right)_{3}$ have been obtained with the high-temperature $\beta$-form tetragonal crystal structure, and the structure refinement based on roomtemperature single-crystal X-ray diffraction data has been performed.

According to the single-crystal experiment, dysprosium molybdate shows tetragonal symmetry at room temperature, space group $P \overline{4} 2_{1} m$, with unit-cell parameters $a=7.295$ (2) $\AA$ and $c=10.578$ (4) $\AA$. On the one hand, the reason for the existence of the tetragonal high-temperature structure at room temperature is not clear, because a monoclinic form of $\mathrm{Dy}_{2}\left(\mathrm{MoO}_{4}\right)_{3}$ has been observed below $1043 \mathrm{~K}$ (Nassau et al., 1971). On the other hand, the symmetry of the low-temperature forms of related compounds is strongly dependent on the synthesis conditions and cation stoichiometry. For example, for the Nd-substituted phase $\left(\mathrm{Nd}_{0.023} \mathrm{Gd}_{0.977}\right)_{2}\left(\mathrm{MoO}_{4}\right)_{3}$, obtained by the Czochralsky method, a tetragonal crystal structure was found at room temperature by Zou et al. (1999). Even a 2\% cation substitution of Gd through Nd stabilizes a high-temperature form in the space group $P \overline{4} 2_{1} m$ with $a=$ 7.356 (1) $\AA$ and $c=10.685$ (2) $\AA$. The tetragonal $\mathrm{Dy}_{2}\left(\mathrm{MoO}_{4}\right)_{3}$ form, obtained in the present work, is stable at room temperature for at least three months (the structure investigation was repeated after three months in storage). The stabilization of the tetragonal structure could be due to a small replacement of Dy by $\mathrm{Zr}$ atoms, analogous to $\left(\mathrm{Nd}_{0.023} \mathrm{Gd}_{0.977}\right)_{2}-$ $\left(\mathrm{MoO}_{4}\right)_{3}$. However, the refinement of the $\mathrm{Dy}_{2}\left(\mathrm{MoO}_{4}\right)_{3}$ structure does not indicate the presence of $\mathrm{Zr}$ on Dy sites to within $1 \%$ accuracy.

The field stability regions for the various types of $R_{2}\left(\mathrm{MoO}_{4}\right)_{3}$ structures, shown by Nassau et al. (1971), depend on temperature and the radius of the rare earth cation. The present $\mathrm{Dy}_{2}\left(\mathrm{MoO}_{4}\right)_{3}$ compound is situated between $\mathrm{Gd}_{2}$ $\left(\mathrm{MoO}_{4}\right)_{3}$, which has the metastable $\beta^{\prime}$-phase at room temperature, and $\mathrm{Y}_{2}\left(\mathrm{MoO}_{4}\right)_{3}$, which has a tetragonal modification in the extended temperature region down to room temperature. The crystal structure of $\mathrm{Dy}_{2}\left(\mathrm{MoO}_{4}\right)_{3}$ is formed by corner-sharing $\mathrm{MoO}_{4}$ tetrahedra and Dy polyhedra coordinated by seven $\mathrm{O}$ atoms (Figs. 1 and 2). In this structure, there are two types of Mo tetrahedra, a regular one and a distorted one, with average $\mathrm{Mo}-\mathrm{O}$ distances of 1.743 (7) and 1.76 (5) $\AA$, respectively. The $\mathrm{DyO}_{7}$ polyhedron is characterized by Dy $-\mathrm{O}$ distances in the range 2.243 (6)-2.393 (5) $\AA$ (Table 1), slightly shorter than those for the coordination polyhedron of $\mathrm{Gd}$ in the previously published $\left(\mathrm{Nd}_{0.023^{-}}\right.$ $\left.\mathrm{Gd}_{0.977}\right)_{2}\left(\mathrm{MoO}_{4}\right)_{3}$ structure mentioned above [2.258(12)$2.418(8) \AA]$. Such compression of the structure can be explained by the slightly smaller size of the $\mathrm{Dy}^{3+}$ cation $(0.97 \AA)$ compared with the $\mathrm{Gd}^{3+}$ cation $(1.0 \AA)$, according to the Shannon ionic radii (Shannon, 1976). For another molybdate, $\mathrm{Dy}_{2} \mathrm{MoO}_{6}$, with the $\mathrm{Mo}^{\mathrm{VI}}$ oxidation state, longer Dy-O interatomic distances $[2.381(6), 2.401(7)$ and $2.421(7) \AA]$ lead to an eightfold oxygen coordination of Dy (Alonso et al., 2004).

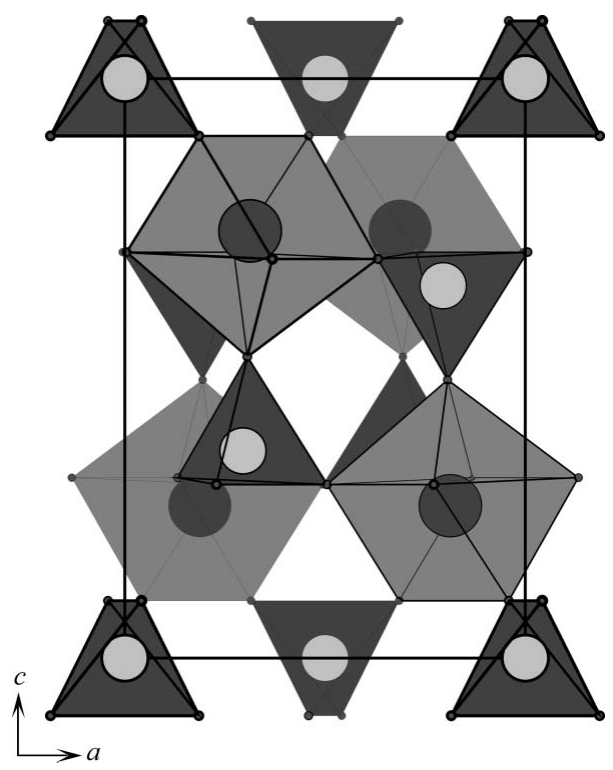

Figure 2

The structural model of $\mathrm{Dy}_{2}\left(\mathrm{MoO}_{4}\right)_{3}$, viewed along the $b$ axis. Dark-grey tetrahedra are formed by Mo atoms and light-grey polyhedra by Dy atoms. The positions for atoms $\mathrm{O} 3, \mathrm{O} 4 A$ and $\mathrm{O} 4 B$ were taken as the average between two close values.

Nassau et al. (1971) systematized the crystal structures of $R_{2}\left(\mathrm{MoO}_{4}\right)_{3}$ according to their rare earth ionic radii and oxygen coordination polyhedra $R \mathrm{O}_{x}$. For example, eightfold oxygen coordination is characteristic for the $A$ family of $R_{2}\left(\mathrm{MoO}_{4}\right)_{3}$ with large rare earth cations such as $\mathrm{La}$, Pr or Pm, and scheelite- or pseudoscheelite-type structures. Due to the shorter Dy-O distances in the tetragonal form of $\mathrm{Dy}_{2}\left(\mathrm{MoO}_{4}\right)_{3}$, one would expect a sixfold oxygen coordination of Dy and an orthorhombic crystal structure like $\mathrm{Er}_{2}\left(\mathrm{MoO}_{4}\right)_{3}$, but the slightly disordered oxygen positions do not distort the structure symmetry and maintain the $\mathrm{DyO}_{7}$ coordination. Disordered atoms $\mathrm{O} 3$ and $\mathrm{O} 4$ make the structure more flexible, atom $\mathrm{O} 3$ lying in the vicinity of a mirror plane and atom $\mathrm{O} 4$ on a general position. The distance from atom $\mathrm{O} 3$ to its mirror image is 0.44 (3) $\AA$, and this seems advantageous for sevenfold oxygen coordination.

The shortest metal-metal distances in the title structure are $\mathrm{Dy} 1 \cdots \mathrm{Mo}^{\mathrm{ii}}=3.7343$ (15) $\AA$, Dy1 $\cdots$ Dy $1^{\mathrm{ii}}=3.8572$ (17) $\AA$ and Mo1 $\cdots \mathrm{Mo}^{\mathrm{ii}}=4.243$ (3) $\AA$ [symmetry code: (ii) $-y+1, x$, $-z+1]$.

\section{Experimental}

Single crystals of $\mathrm{Dy}_{2}\left(\mathrm{MoO}_{4}\right)_{3}$ were obtained during an investigation of the $\mathrm{Dy}_{2} \mathrm{O}_{3}-\mathrm{ZrO}_{2}-\mathrm{MoO}_{3}$ phase diagram in an evacuated sealed silica tube from a $\mathrm{Dy}_{2} \mathrm{Zr}\left(\mathrm{MoO}_{4}\right)_{5}$ composition by heating to $1273 \mathrm{~K}$, followed by cooling at a rate of $5 \mathrm{~K} \mathrm{~h}^{-1}$ to $1073 \mathrm{~K}$, after which the tube was cooled to room temperature by switching off the heating. From the resulting multiphase polycrystalline mixture, colourless single crystals of $\mathrm{Dy}_{2}\left(\mathrm{MoO}_{4}\right)_{3}$ were selected using an optical microscope. 


$\begin{array}{ll}\text { Crystal data } & \\ \mathrm{Dy}_{2} \mathrm{Mo}_{3} \mathrm{O}_{12} & Z=2 \\ M_{r}=804.82 & \mathrm{Mo} K \alpha \text { radiation } \\ \text { Tetragonal, } P \overline{4}{ }_{1} m & \mu=16.41 \mathrm{~mm}^{-1} \\ \begin{array}{l}a=7.295(2) \AA \\ c=10.578(4) \AA\end{array} & T=296 \mathrm{~K} \\ V=562.9(3) \AA^{3} & 0.08 \times 0.06 \times 0.06 \mathrm{~mm} \\ & \\ \text { Data collection } & \\ \text { Bruker Kappa APEXII CCD area- } & 2641 \text { measured reflections } \\ \quad \text { detector diffractometer } & 723 \text { independent reflections } \\ \text { Absorption correction: multi-scan } & 645 \text { reflections with } I>2 \sigma(I) \\ \quad(S A D A B S ; \text { Bruker, } 2004) & R_{\text {int }}=0.054 \\ \quad T_{\text {min }}=0.319, T_{\text {max }}=0.374 & \\ \text { Refinement } & \\ R\left[F^{2}>2 \sigma\left(F^{2}\right)\right]=0.029 & \\ w R\left(F^{2}\right)=0.045 & \Delta \rho_{\text {max }}=1.04 \text { e } \AA^{-3} \\ S=0.97 & \Delta \rho_{\text {min }}=-0.88 \text { e } \AA^{-3} \\ 723 \text { reflections } & \text { Absolute structure: Flack }(1983), \\ 44 \text { parameters } & \text { with } 287 \text { Friedel pairs } \\ & \text { Flack parameter: } 0.02(2)\end{array}$

Due to the large atomic displacement parameters, a split position from the original position on a mirror plane was introduced for atom $\mathrm{O} 3$, with an occupancy of 0.5 . Atom $\mathrm{O} 4$ was disordered over two sites (O4A and $\mathrm{O} 4 B$ ) separated by 0.63 (2) $\AA$. Atoms $\mathrm{O} 4 A$ and $\mathrm{O} 4 B$ were refined with a common displacement parameter and their occupancy factor was constrained to sum to 1 . These positions (O3, O4A and $\mathrm{O} 4 B$ ) were then refined with isotropic displacement parameters.

Data collection: APEX2 (Bruker, 2004); cell refinement: SAINT (Bruker, 2004); data reduction: $S A I N T$; $\operatorname{program}(\mathrm{s})$ used to solve structure: SHELXS97 (Sheldrick, 2008); program(s) used to refine structure: SHELXL97 (Sheldrick, 2008); molecular graphics: DIAMOND (Brandenburg, 2008); software used to prepare material for publication: SHELXL97.

This work was supported by the Deutscher Akademischer Austauschdienst (DAAD) (postdoctoral fellowship grant to $\mathrm{SD)}$.
Table 1

Selected bond lengths and contact distances (£).

\begin{tabular}{|c|c|c|c|}
\hline Dy1-O2 & $2.243(6)$ & $\mathrm{Mo} 1-\mathrm{O} 4 B$ & $1.697(13)$ \\
\hline Dy1-O3 & $2.304(9)$ & Mo1-O3 & $1.745(9)$ \\
\hline $\mathrm{Dy} 1-\mathrm{O} 4 A^{\mathrm{i}}$ & $2.307(15)$ & Mo1-O1 & $1.784(8)$ \\
\hline $\mathrm{Dy} 1-\mathrm{O} 4 B^{\mathrm{i}}$ & $2.351(14)$ & $\mathrm{Mo} 1-\mathrm{O} 4 A$ & $1.803(16)$ \\
\hline $\mathrm{Dy} 1-\mathrm{O} 1^{\mathrm{ii}}$ & $2.393(5)$ & $\mathrm{Mo} 2-\mathrm{O} 2$ & $1.743(7)$ \\
\hline
\end{tabular}

Symmetry codes: (i) $y,-x+1,-z+1$; (ii) $-y+1, x,-z+1$.

Supplementary data for this paper are available from the IUCr electronic archives (Reference: LG3065). Services for accessing these data are described at the back of the journal.

\section{References}

Alonso, J. A., Rivillas, F., Martínez-Lope, M. J. \& Pomjakushin, V. (2004). J. Solid State Chem. 177, 2470-2476.

Borchardt, H. J. \& Bierstedt, P. E. (1967). J. Appl. Phys. 38, 2057-2061.

Brandenburg, K. (2008). DIAMOND. Crystal Impact GbR, Bonn, Germany. Brixner, L. H. (1973). J. Cryst. Growth, 18, 297-302.

Bruker (2004). APEX2 (Version 1.08), SAINT (Version 7.03) and SADABS (Version 2.11). Bruker AXS Inc., Madison, Wisconsin, USA.

Flack, H. D. (1983). Acta Cryst. A39, 876-881.

Gall, P., Barrier, N., Gautier, R. \& Gougeon, R. (2002). Inorg. Chem. 41, 28792885.

Jeitschko, W. (1972). Acta Cryst. B28, 60-76.

Keve, E. T., Abrahams, S. C., Nassau, K. \& Glass, A. M. (1970). Solid State Commun. 8, 1517-1520.

Nassau, K., Shiever, J. W. \& Keve, E. T. (1971). J. Solid State Chem. 3, 411419.

Roy, M., Choudhary, R. N. P. \& Acharya, H. N. (1989). J. Therm. Anal. 35, 1471-1476.

Shannon, R. D. (1976). Acta Cryst. A32, 751-767.

Sheldrick, G. M. (2008). Acta Cryst. A64, 112-122.

Smet, F. D., Ruiz, P., Delmon, B. \& Devillers, M. (2001). J. Phys. Chem. 105, 12355-12363.

Wang, X., Xian, Y., Wang, G., Shi, J., Su, Q. \& Gong, M. (2008). Opt. Mater. 133, 33-39.

Wenxing, K., Yining, F., Kaidong, C. \& Yi, C. (1999). J. Catal. 186, 310-317.

Zou, Y.-Q., Chen, L., Gao, X.-Y., Tang, D.-Y. \& Luo, Z.-D. (1999). Chin. J. Struct. Chem. 18, 447-450. 